Tropical Journal of Pharmaceutical Research April 2019; 18 (4): 697-702

ISSN: $1596-5996$ (print); 1596-9827 (electronic)

(C) Pharmacotherapy Group, Faculty of Pharmacy, University of Benin, Benin City, 300001 Nigeria.

\title{
Co-crystallization of quercetin and isonicotinamide using solvent evaporation method
}

\author{
Budipratiwi Wisudyaningsih $^{1,2}$, Dwi Setyawan ${ }^{1 \star}$ Siswandono $^{1}$ \\ ${ }^{1}$ Faculty of Pharmacy, Universitas Airlangga, Surabaya, ${ }^{2}$ Faculty of Pharmacy Jember University, Jember, Indonesia \\ ${ }^{*}$ For correspondence: Email: dwisetyawan-90@ff.unair.ac.id; Tel: +6231-5033710; Fax: +62-31-5020514
}

Sent for review: 16 October 2018

Revised accepted: 16 March 2019

\begin{abstract}
Purpose: To obtain quercetin-isonicotinamide co-crystal (CQINA) with improved physicochemical and in-vitro dissolution characteristics.

Methods: Co-crystallization of quercetin $(Q)$ and isonicotinamide (INA) in molar ratio of 1:1 was performed using solvent evaporation method with the addition of $50 \mathrm{~mL}$ of ethanol $(99.9 \%, \mathrm{v} / \mathrm{v})$. The resultant solution was thoroughly mixed and stirred at room temperature for $48 \mathrm{~h}$ to slowly evaporate the solvent until CQINA was obtained. The co-crystal phase was characterized using differential scanning calorimetry (DSC), powder x-ray diffractometry (PXRD), scanning electron microscopy (SEM), and fourier transform infrared (FTIR) spectroscopy. In-vitro dissolution was performed by USP method II in $900 \mathrm{~mL}$ citrate buffer ( $\mathrm{pH} 5.0 \pm 0.05$ ), with stirring at $100 \mathrm{rpm}$ and at $37 \pm 0.5^{\circ} \mathrm{C}$.

Results: Computational approach predicted the formation of hydrogen bonds between $Q$ and coformers used, and the interaction involved minimum energy. In CQINA thermogram, a new endothermic peak was formed with a melting point of $255.26{ }^{\circ} \mathrm{C}$, while $Q\left(314.85{ }^{\circ} \mathrm{C}\right)$ and INA $\left(156.62{ }^{\circ} \mathrm{C}\right)$. Images from DSC, PXRD, SEM and FTIR showed that the crystal habits and morphologies of the CQINA differed from those of the original components. There was an improvement in the dissolution profile of CQINA, when compared with those of the original components.

Conclusion: $Q$ and INA subjected to solvent evaporation result in the formation of a CQINA with different crystal habit, which possess physicochemical characteristics different from those of its constituents. Modification of Q crystals in CQINA increases its in vitro dissolution, making it a potential pharmaceutical agent.
\end{abstract}

Keywords: Quercetin, Cocrystal, Isonicotinamide, Solvent evaporation, Crystalline, Dissolution

\begin{abstract}
This is an Open Access article that uses a fund-ing model which does not charge readers or their institutions for access and distributed under the terms of the Creative Commons Attribution License (http://creativecommons.org/licenses/by/4.0) and the Budapest Open Access Initiative (http://www.budapestopenaccessinitiative.org/read), which permit unrestricted use, distribution, and reproduction in any medium, provided the original work is properly credited.
\end{abstract}

Tropical Journal of Pharmaceutical Research is indexed by Science Citation Index (SciSearch), Scopus, International Pharmaceutical Abstract, Chemical Abstracts, Embase, Index Copernicus, EBSCO, African Index Medicus, JournalSeek, Journal Citation Reports/Science Edition, Directory of Open Access Journals (DOAJ), African Journal Online, Bioline International, Open-J-Gate and Pharmacy Abstracts

\section{INTRODUCTION}

Quercetin is a flavonoid possesses antioxidant, anti-cancer, anti-viral, anti-obesity, anti-bacterial and anti-inflammatory properties [1-5]. It is classified as a class II compound according to Biopharmaceutics Classification System (BCS) and is included in the Generally Recognized as Safe (GRAS) material [6,7]. Quercetin is highly soluble in ethanol, and dimethyl sulfoxide (DMSO) and sparingly soluble in water $[8,9]$. This poor aqueous solubility characteristic significantly decreases its absorption in the gastrointestinal tract (GIT), thus lowering its bioavailability and 
resulting in failure to attain the desired therapeutic effect on oral use [10].

Co-crystallization is a strategy that can be used to increase the solubility of a compound. Pharmaceutical co-crystals contain two or more distinct molecules assembled to create a new crystal with good water solubility, relative to those of the pure compounds. Co-crystals are solid that are crystalline, single phase materials composed of two or more different molecular or ionic compounds generally in stoichiometric ratios which are neither solvates nor simple salts [11]. Interactions involved in co-crystal formation are hydrogen bonds, Van der Waals forces, and $\pi-\Pi^{*}$ interactions [12].

The aim of this study was to determine possible interaction between quercetin and several coformers through a computational approach, and obtain quercetin-isonicotinamide co-crystal (CQINA) with increased physicochemical and in vitro dissolution characteristics. The characterization of co-crystal formed was done using PXRD, DSC, SEM, FTIR, and in-vitro dissolution test to determine the changes in quercetin physicochemical characteristics.

\section{EXPERIMENTAL}

\section{Materials}

Quercetin and INA were obtained from Tokyo Chemical Industry (Japan), while absolute ethanol was purchased from Sigma-Aldrich (France). Differential scanning calorimeter was a product of Mettler (Switzerland) and powder Xray diffractometer was obtained from Philip X'Pert (Netherlands). Scanning electron microscope was purchased from Hitachi Co., Ltd. (Japan); infrared (IR) spectrophotometer was a product of Jasco (Japan), while UV-Visible spectrophotometer was purchased from Genesys (USA).

\section{Prediction of co-crystal formation}

\section{Computational approach}

This computational approach was performed using Marvin Sketch 5.2.5.1 and ChemBioDraw Ultra 12.0 to visualize hydrogen bond interaction between quercetin and the co-formers. Computational approach was also carried out to determine total energy, which is measure of the ability of quercetin and the co-formers to form hydrogen bonds. The co-formers used included: tartaric acid, maleic acid, mannitol, saccharin, nicotinamide, isonicotinamide (INA), lysin, and arginine.

\section{Crystallization reaction}

The formation of new crystals through physical interactions between the two components was carried out using heat contact method [13]. Crystalline behavior of each component and the results of quercetin and INA crystal physical interactions were observed using a polarized light microscope.

\section{Binary phase diagramming}

Quercetin-INA binary phase diagram was drawn by observing the endothermic peak formed in quercetin-INA physical mixture. The endothermic peak was obtained from the profile of DSC thermogram.

\section{Preparation of CQINA}

The CQINA was prepared using solvent evaporation method [13]. Quercetin and INA (1: 1 molar ratio) were dissolved in $50 \mathrm{~mL}$ absolute ethanol $(99.9 \% \mathrm{v} / \mathrm{v})$. The resultant solutions was thoroughly mixed and stirred at room temperature for $48 \mathrm{~h}$ slowly evaporate the solvent until CQINA was obtained.

\section{Characterization of CQINA}

\section{Thermal analysis}

Portions of CQINA was put in an aluminum pan, and subjected to DSC at heating speed of 5 ${ }^{\circ} \mathrm{C} / \mathrm{min}$ within a temperature range of $30-350{ }^{\circ} \mathrm{C}$. The melting point of the sample was determined from the profile of the thermogram.

\section{Crystallinity test}

Analysis of CQINA crystalline phase was carried out using powder X-ray diffraction with the following conditions: $\mathrm{Cu}$ monochromator, $40 \mathrm{kV}$ voltage, current of $30 \mathrm{~mA}$, and 0.2 inch slit width. Data was collected in scanning mode of $0.2^{\circ}$ $0.5^{\circ}$ per min in $2 \theta$ range of $5^{\circ}-40^{\circ}$ at room temperature.

\section{Crystal morphology}

Characterization of crystal morphology was performed using SEM. Powdered samples of CQINA were put in sample holder and coated with gold to a thickness of $10 \mathrm{~nm}$. They were then observed at various magnifications at a regulated working voltage of $20 \mathrm{kV}$ and a current of $12 \mathrm{~mA}$. Comparison of CQINA crystal morphology was made with those of quercetin and INA crystals. 


\section{Vibrational transition}

Vibrational transitions were observed and analyzed using IR spectrophotometer. The samples were mixed with $\mathrm{KBr}$ crystal $(1: 100)$, homogenize and then subjected to pressing at 20 psi. The spectra were measured using Jasco4200 FTIR spectrometer and observed in the absorption band or wavelength of $4000-450 \mathrm{~cm}$ 1. The resultant CQINA FTIR spectra were compared with those of quercetin and INA.

\section{Dissolution test}

This was performed on quercetin, physical mixture of quercetin-INA, and CQINA obtained from solvent evaporation. Each weighed sample was equivalent to $20 \mathrm{mg}$ quercetin. In vitro dissolution was performed using USP method II in $900 \mathrm{~mL}$ citrate buffer $(\mathrm{pH} 5.0 \pm 0.05)$ stirred at $100 \mathrm{rpm}$ and temperature of $37^{\circ} \mathrm{C}$. Aliquots of the samples $(5.0 \mathrm{~mL})$ were withdrawn intermittently at intervals of $5,10,15,30,45$, and $60 \mathrm{~min}$, and filtered with a $0.45 \mu \mathrm{m}$ cellulose filter membrane [14]. Absorbance of each sample was read in a UV-Visible spectrophotometer at maximum wavelength.

\section{Statistical analysis}

Data are expressed as mean $\pm S D$, and statistical analysis was performed using SPSS (18.0). One-way analysis of variance (ANOVA) was performed for multiple comparison. Statistical significance showed with $p$ value < 0.05 . Winplotr was used for processing and analyzing powder x-ray diffraction data, while Marvin Sketch 5.2.5.1 and ChemBioDraw Ultra 12.0 were used for visualizing and predicting hydrogen bond interactions between quercetin and the co-formers.

\section{RESULTS}

\section{Outcome of CA}

Computational approach predicted the formation of hydrogen bonds between quercetin and coformers used, and interaction involved minimum energy: tartaric acid $(66.3288 \mathrm{kcal} / \mathrm{mol})$, maleic acid (35.6241 kcal / mol), mannitol (1052.85 $\mathrm{kcal} / \mathrm{mol})$, lysine $(53.6929 \mathrm{kcal} / \mathrm{mol})$, arginine $(85.3495 \mathrm{kcal} / \mathrm{mol})$, saccharin $(44.1072 \mathrm{kcal} / \mathrm{mol})$, nicotinamide $(41.5672 \mathrm{kcal} / \mathrm{mol})$, and isonicotinamide $(20.0104 \mathrm{kcal} / \mathrm{mol})$. These results are shown in Figure 1.

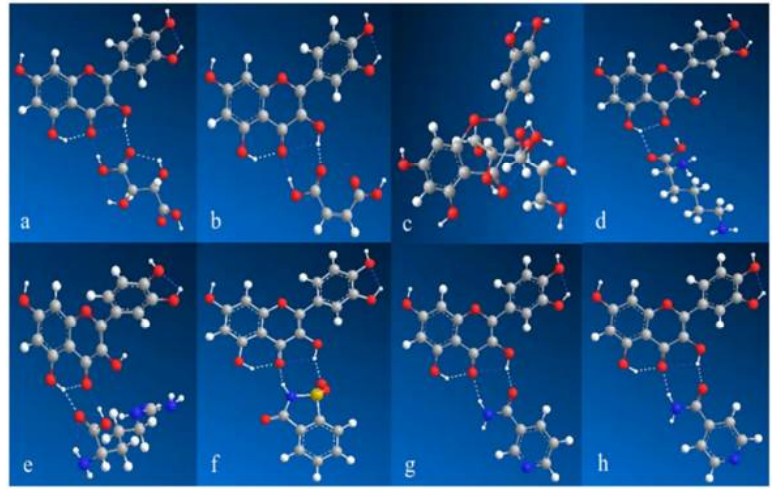

Figure 1: Prediction of hydrogen bonds formation between quercetin and the co-formers: (a) tartaric acid, (b) maleic acid; (c) mannitol; (d) lysine; (e) arginine; (f) saccharin; (g) nicotinamide; (h) isonicotinamide (INA)

\section{Crystal interaction}

Physical interactions between quercetin and INA are shown in Figure 2. The shapes of the new crystals formed were indicative of quercetin cocrystals. Polarization microscopy revealed the presence of new crystalline behavior different from those of its original components.

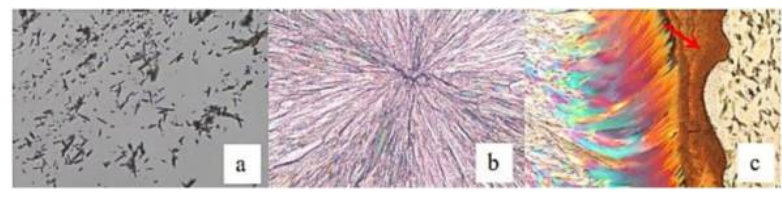

Figure 2: Photomicrographs showing crystal behavior as revealed by polarizing light microscope (x 200). (a) Quercetin; (b) INA; and (c) Quercetin-INA.

\section{Binary phase diagram of quercetin-INA}

Binary phase diagram was drawn to confirm the existence of physical interactions between quercetin and INA, forming co-crystal. As shown in Figure 3, there was formation of new endothermic peaks and congruent melting points at $260.62{ }^{\circ} \mathrm{C}$.

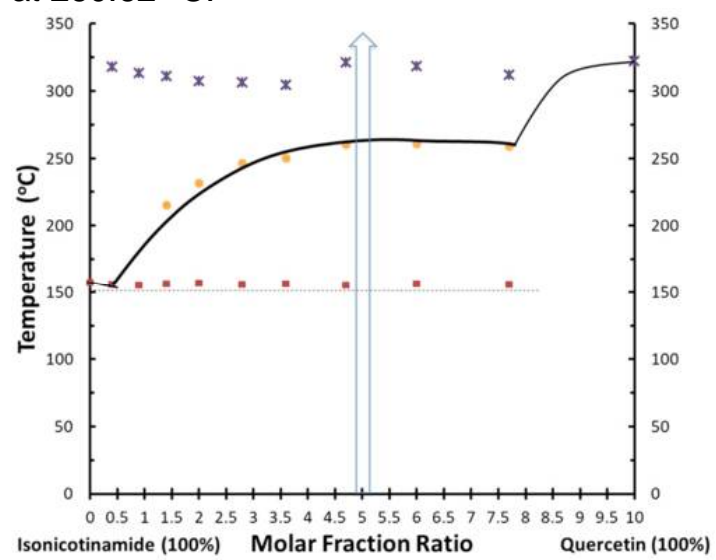

Figure 3: Diagram of quercetin-INA binary system

Trop J Pharm Res, April 2019; 18(4): 699 


\section{DSC thermograms}

As shown in Figure 4, DSC thermograms revealed differences in endothermic peaks between quercetin, INA, and CQINA. In CQINA thermogram, a new endothermic peak was formed at a melting point of $255.26{ }^{\circ} \mathrm{C}$, while quercetin $\left(314.85{ }^{\circ} \mathrm{C}\right)$ and INA $\left(156.62{ }^{\circ} \mathrm{C}\right)$ endothermic peaks were not observed in CQINA thermogram.

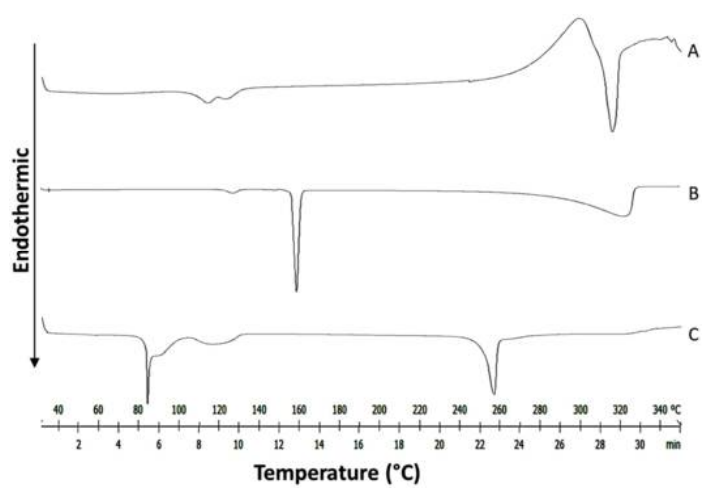

Figure 4: Profiles of DSC thermograms (A) Quercetin; (B) INA; and (C) CQINA

\section{Powder x-ray diffractograms}

As shown in Figure 5, there were differences in diffraction peaks between quercetin, INA, and CQINA. New and distinct interference peaks were formed in CQINA at an angle of 20: $6.19^{\circ}$ (25.38\%); $7.72^{\circ}$ (11.29\%); $17.18^{\circ}(22.39 \%)$; $23.94^{\circ}(21.87 \%)$; and $24.04^{\circ}(21.92 \%)$. These differences were indicative of co-crystal formation, since new crystalline phases were produced.

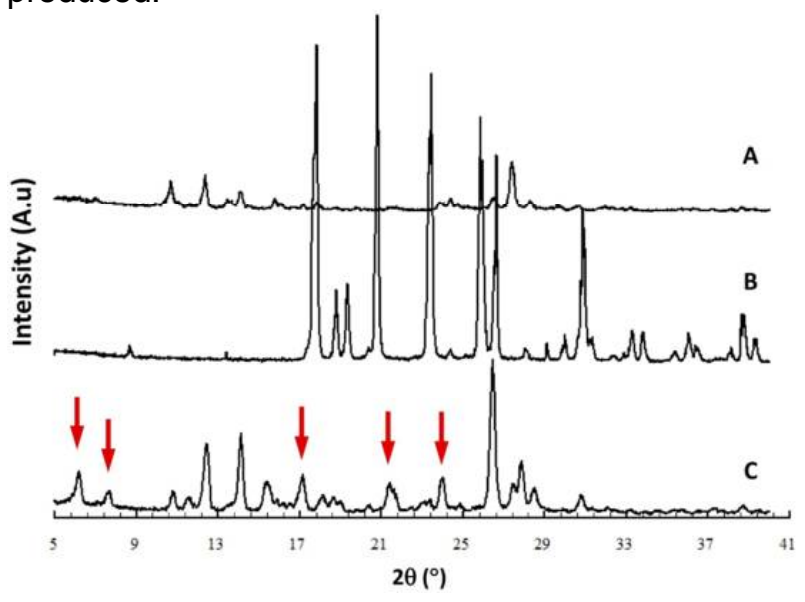

Figure 5: Powder X-ray diffractograms of (A) Quercetin; (B) INA; and (C) CQINA

\section{Crystal morphology}

Quercetin exhibited crystalline habit with prism- like shape (size of about $20-100 \mu \mathrm{m}$ ), while INA exhibited crystal habit in the form of an angular shape with size range of $100-300 \mu \mathrm{m}$. The crystal habit of CQINA was different from those of its original components, and was needleshaped (Figure 6).

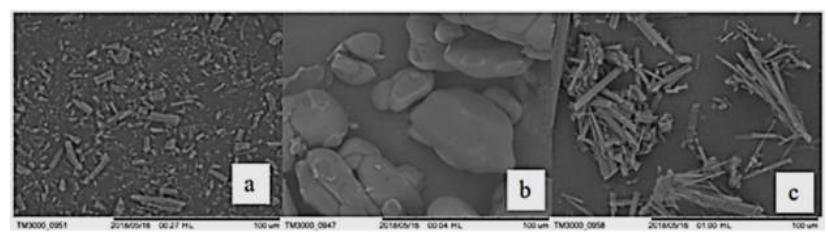

Figure 6: Photomicrographs of samples as revealed in SEM (x 1000). (a) Quercetin; (b) INA; and (c) CQINA

\section{FTIR spectra}

The FTIR spectrum of CQINA was different from those of its original components. Quercetin spectrum revealed $\mathrm{OH}$-group at $3413.52 \mathrm{~cm}^{-1}$ and $\mathrm{C}=\mathrm{O}$ group at $1667.62 \mathrm{~cm}^{-1}$. The spectrum of INA revealed $\mathrm{NH}_{2}$ group at $3371.33 \mathrm{~cm}^{-1}$ and $3186.38 \mathrm{~cm}^{-1}$, and $\mathrm{C}=\mathrm{O}$ groups at $1668.39 \mathrm{~cm}^{-1}$. The spectrum of CQINA also revealed $\mathrm{OH}-$ group shift from 3319.51 to $3215.52 \mathrm{~cm}^{-1}$ and $\mathrm{C}=$ $O$ group stretching at $1688.47 \mathrm{~cm}^{-1}$ and 1653.46 $\mathrm{cm}^{-1}$. The $\mathrm{NH}_{2}$ group in INA was not obvious in CQINA spectrum (Figure 7).

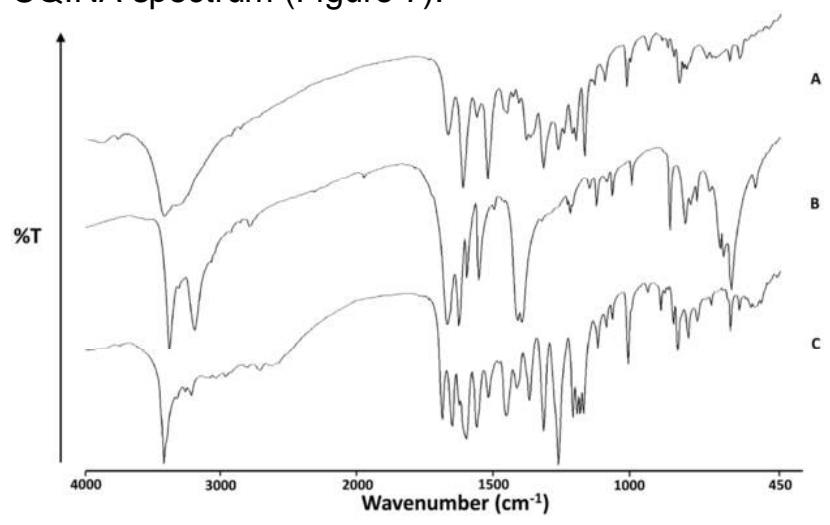

Figure 7: FTIR spectra of samples. (A) Quercetin; (B) INA; and (C) CQINA.

\section{Dissolution profiles}

Quercetin, quercetin-INA physical mixture, and CQINA dissolution profiles are shown in Figure 8. The dissolution profile of CQINA revealed an improvement when compared with those of its original components. After $60 \mathrm{~min}$, the percentage dissolution of quercetin and INA were $76.7 \pm 1.15$ and $75.8 \pm 0.19$, respectively. The invitro dissolution of CQINA was $83.3 \pm 1.38 \%$ within 60 min. 


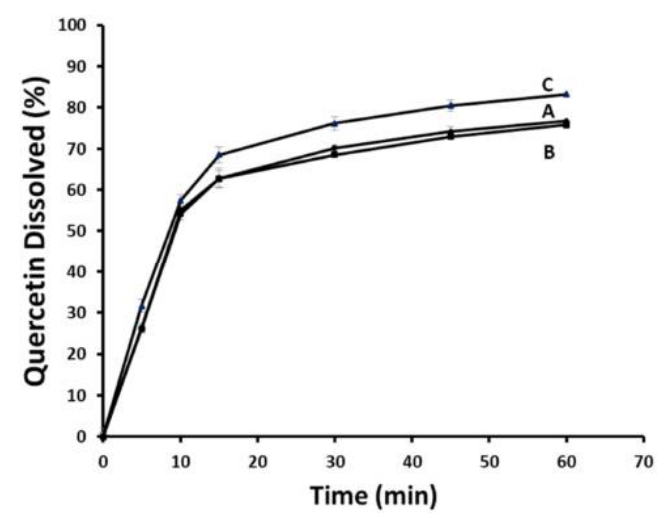

Figure 8: Dissolution profiles of samples. (A) Quercetin; (B) Quercetin-INA physical mixture; and (C) CQINA

\section{DISCUSSION}

In the present study, CA was employed to predict the formation of co-crystal between quercetin and eight potential compounds as co-formers. Computational approach (CA) can predict the most stable interaction form of supramolecular heterosynthone assembly of quercetin and the co-formers. The results showed that INA had the lowest minimized energy, indicative of the most stable form of interaction.

Polarization microscopy revealed the formation of new crystals at the meeting point between quercetin and INA crystals, whose shape and color were different from those of its original components. This result suggests that the new crystal shape may be that of a co-crystal.

Results of DSC revealed several endothermic peaks which formed a congruent system. The formation of a new endothermic peak which was a congruent melting point or co-crystal melting point served as an initial indicator of the formation of a co-crystal. Studies have shown that in some drug combinations, the formation of several endothermic peaks is an early indication of the formation of a co-crystal from the physical mixture [15].

The thermal properties of CQINA as revealed by DSC showed the presence of new endothermic peaks with melting points that were between those of quercetin and INA. This implies the formation of a new solid phase with different thermal properties from those of the original components [16].

In this study, characterization using PXRD revealed the formation of a new solid phase different from the diffractograms of the original components. These results are in agreement with those reported previously [17]. Differences in profiles of diffractograms were revealed by the emergence of new diffraction peaks and the loss of specific diffraction peaks from the constituents. These results suggest formation of CQINA.

The shape and size of crystals affect physicochemical characteristics of a solid material such as melting point, solubility, and PXRD profile. The results of SEM indicate that CQINA has a different crystal shape and size when compared to those of its constituents. These results suggest the formation of a cocrystal with new crystal morphology and physicochemical characteristics.

Co-crystals are formed through the interaction between two or more compounds via hydrogen bonds [12]. In this study, the hydrogen bonds formed in CQINA were revealed by FTIR spectra. The wavelength of $\mathrm{OH}$-group in quercetin shifted from 3413.52 to $3215.52 \mathrm{~cm}^{-1}$ in CQINA spectrum. The $\mathrm{C}=\mathrm{O}$ group shift in quercetin also appeared from 1667.62 to $1688.47 \mathrm{~cm}^{-1}$ in CQINA spectrum. However, the $\mathrm{NH}_{2}$ group in INA spectrum which peaked at 3371.33 and $3186.38 \mathrm{~cm}^{-1}$ was not observed in CQINA spectrum. It is likely that the $\mathrm{NH}_{2}$ group was involved in hydrogen bonds formation with the $\mathrm{OH}$ group on ring $\mathrm{A}$ of quercetin, thus becoming the $\mathrm{NH}$ group that peaked at $3416.39 \mathrm{~cm}^{-1}$ in the CQINA spectrum.

A shifting and loss of peaks in $\mathrm{NH}_{2}$ groups showed that the hydrogen bonds interaction between $\mathrm{OH}$ groups in quercetin and $\mathrm{NH}_{2}$ groups in INA formed CQINA.

Dissolution of drugs with very low water solubility is usually the rate-limiting step in the absorption of such drugs in the GIT. Therefore the dissolution of compounds that are sparingly soluble in water can be used to predict their bioavailability. The dissolution of CQINA was slightly increased, relative to those of quercetin and physical mixture of quercetin and INA $(p<$ 0.05). Changes in crystal physicochemical properties caused by quercetin interaction with INA produced CQINA with higher dissolution than that of pure quercetin.

\section{CONCLUSION}

These results indicate that quercetin and INA (1:1 molar ratio) subjected to solvent evaporation result in the formation of a co-crystal (CQINA) with crystal habits and physicochemical characteristics different from those if its constituents. Modification of quercetin crystals in CQINA increases its in-vitro dissolution, thus making it a potential pharmaceutical agent. 


\section{DECLARATIONS}

\section{Acknowledgement}

This work was supported with grants from the Directorate General of Resources for Science, Technology and Higher Education, Ministry of Research, Technology and Higher Education (KEMENRISTEK DIKTI) with scheme of scholarship funding of $\mathrm{PhD}$ program at Airlangga University, Surabaya, Indonesia. The authors would like to acknowledge with thanks the Faculty of Pharmacy, Airlangga University and Jember University for assistance with laboratory facilities.

\section{Conflict of Interest}

No conflict of interest associated with this work.

\section{Contribution of Authors}

The authors declare that this work was done by the authors named in this article and all liabilities pertaining to claims relating to the content of this article will be borne by them.

\section{Open Access}

This is an Open Access article that uses a funding model which does not charge readers or their institutions for access and distributed under the terms of the Creative Commons Attribution License (http://creativecommons.org/licenses/by/ 4.0) and the Budapest Open Access Initiative (http://www.budapestopenaccessinitiative.org/rea d), which permit unrestricted use, distribution, and reproduction in any medium, provided the original work is properly credited.

\section{REFERENCES}

1. Duenas M, Gonzalez-Manzano S, Gonzalez-Paramas A, and Santos-Buelga C. Antioxidant evaluation of $\mathrm{O}$ methylated metabolites of catechin, epicatechin and quercetin. J Pharm Biomed Anal. 2010; 51: 443-449.

2. Nabavi S F, Russo G L, Daglia M, Nabavi S M. Role of quercetin as an alternative for obesity treatment: You are what you eat! Food Chem. 2015; 179: 305-310.

3. Kumari A, Yadav $S K$, Pakade $Y B$, Singh B, Yadav $S C$. Development of biodegradable nanoparticles for delivery of quercetin. Colloids Surf B Biointerfaces. 2010; 80: 184-192.

4. Anandam S, Selvamuthukumar S. Fabrication of cyclodextrin nanosponges for quercetin delivery:
Physicochemical characterization, photostability, and antioxidant effects. J Mater Sci. 2014; 49: 8140-8153.

5. Rattanachaikunsopon $P$, Phumkhachorn P. Contents and antibacterial activity of flavonoids extracted from leaves of Psidium guajava. J Med Plant Res. 2010; 4: 393-396.

6. Harwood M, Danielewska B, Borzelleca JF, Flamm GW, Williams GM, Lines TC. A Critical Review of the Data Related to the Safety of Quercetin and Lack of Evidence of In Vivo Toxicity, Including Lack of Genotoxic/ Carcinogenic Properties. Food Chem Toxicol. 2007; 45 (11): 2179 - 2205.

7. Knab AM, Shanely RA, Henson DA, Jin F, Heinz $S A$, Austin MD, Nieman DC. Influence of Quercetin Supplementation on Disease Risk Factors in Community-Dwelling Adults. J Am Diet Assoc. 2011; 111(4): 542 - 549.

8. Wang $X$, Ouyang $Y Y$, Liu J, Zhao G. Flavonoid intake and risk of CVD: a systematic review and meta-analysis of prospective cohort studies. Br J Nutr. 2016; 111: 111.

9. Gao L, Liu G, Wang X, LiU F, Xu Y, Ma J. Preparation of a chemically stable quercetin formulation using nanosuspension technology. Int J Pharm. 2011; 404: 231-237.

10. Smith AJ, Kavuru P, Wojtas L, Zaworotko MJ, Shytle RD. Cocrystal of Quercetin with Improved Solubility and Oral Bioavailability. Mol. Pharmaceut 2011; 8(5): 1867 1876.

11. Krisnalah YSR. Pharmaceutical Technologies for Enhancing Oral Bioavailabilities of Poorly Soluble Drugs. J Bioequiv Availab. 2010; 2(2): 28-36.

12. Santos OMM, Reis MED, Jacon JT, Lino MES, Simoes JS, Doriguetto AC. 2014. Polimorphism: An Evaluation of the Potential Risk to the Quality of Drug Products from the Farmacia Popular Rede Propria. Braz J Pharm Sci. 2014; 50 (1): 1-24.

13. Setyawan $D$, Sari $R$, Yusuf $H$, Primaharinastiti $R$. Preparation and Characterization of ArtesunateNicotinamide Cocrystal by Solvent Evaporation and Slurry Method. Asian J Pharm Clin Res. 2014, 7: 62 65.

14. Setyawan $D$, Fadhil $A A$, Juwita $D$, Yusuf $H$, Sari $R$. Enhancement of Solubility and Dissolution Rate of Quercetin with Solid Dispersion System Formation using Hydroxypropyl Methyl Cellulose Matrix. Thai J Pharm Sci. 2017, 41(3): 112 - 116.

15. Yamashita $H$, Hirakura Y, Yuda M, Teramura T, Terada K. Detection of Cocrystal Formation Based on Binary Phase Diagram Using Thermal Analysis. Pharm Res. 2013; 30(1): 70-80.

16. Schultheiss N, Newman A. Pharmaceutical Cocrystals and Their Physicochemical Properties. Cryst Growth Des. 2009; 9(6): 2950 -2967.

17. Setyawan $D$, Jovita $R O$, lqbal $M$, Paramanandana $A$, Yusuf H, Lestari ML. Co-crystalization of quercetin and malonic acid using solvent-drop grinding method. Trop $J$ Pharm Res. 2018; 17(6): 997-1002. 